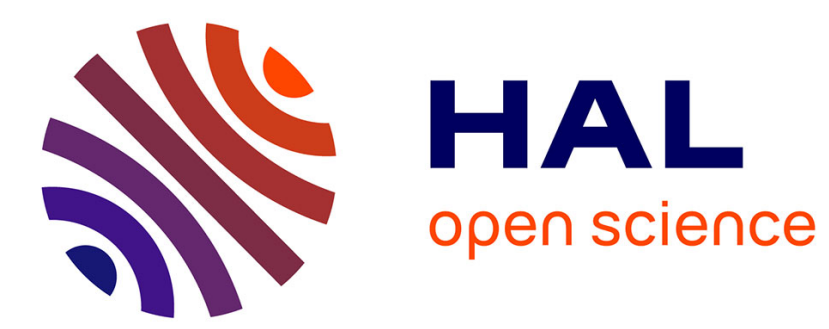

\title{
En librairie - Numéro 1 - 2003
}

- [.]revue Forestière Française, Rédaction

\section{- To cite this version:}

- [.]revue Forestière Française, Rédaction. En librairie - Numéro 1 - $2003 . \quad 2003$, pp.96.

10.4267/2042/5161 . hal-03534579

\section{HAL Id: hal-03534579 \\ https://hal.science/hal-03534579}

Submitted on 19 Jan 2022

HAL is a multi-disciplinary open access archive for the deposit and dissemination of scientific research documents, whether they are published or not. The documents may come from teaching and research institutions in France or abroad, or from public or private research centers.
L'archive ouverte pluridisciplinaire HAL, est destinée au dépôt et à la diffusion de documents scientifiques de niveau recherche, publiés ou non, émanant des établissements d'enseignement et de recherche français ou étrangers, des laboratoires publics ou privés. 


\title{
CHAONIOUE... EN LIBARIRIE
}

\author{
ARMAND (G.), coordonnateur
}

\section{Le Hêtre autrement}

Paris : Institut pour le Développement forestier, 2002. - 263 p., tableaux, graphiques, photographies en couleur, bibliographie, glossaire (ISBN 2-904740-86-4).

Prix : $40 €+6 €$ de frais d'envoi.

Ce manuel est un enrichissement et une actualisation remarquables (car conçu dans une optique différente) du livre "Le Hêtre" paru en 1981 aux éditions de l'INRA.

“Le Hêtre, 1981" s'est voulu monographie complète, à caractère premier scientifique, conçue et réalisée par un groupe important de chercheurs et enseignants de l'INRA (département des recherches forestières) et de l'ENGREF.

"Le Hêtre autrement, 2002" est un manuel technique " résultant de huit années de tournées, travaux et observations du groupe de travail Hêtre de l'Institut pour le Développement forestier », groupe créé en 1994, constitué essentiellement d'excellents et dynamiques gestionnaires de forêts et sylviculteurs.

En 1981, les auteurs se sont efforcés de bien transmettre leurs connaissances, et résultats des recherches, aux praticiens.

Ceux de 2002 ont bien sûr fait appel, lorsqu'il le fallait, à des chercheurs forestiers qualifiés (tel F. Ningre, dont le rôle fut majeur dans la rédaction du livre) et à bien d'autres informateurs "extérieurs".

Mais les buts et méthodes n'étant pas les mêmes, les deux livres ne pouvaient être que très différents : on ne peut qu'apprécier le résultat, car les réalisateurs du manuel en ont fait une réussite véritablement remarquable.

Ils ont eu pour objectif " de fabriquer du Hêtre de haute qualité en 80 à 100 ans, en privilégiant la culture d'arbres individuels, sous le mode régulier ou sous le mode irrégulier et toujours, dans la mesure du possible, à partir de régénérations naturelles » (en cas de nécessaires plantations, toutes recommandations sont précisées, notamment en ce qui concerne les zones d'utilisations des plants, chaque fois de provenance adaptée).

Le manuel est articulé en cinq chapitres et sept annexes, dont voici les titres, avec de courts compléments : Chapitre 1. Les hêtraies en France (notamment autécologie, biologie, fonctionnement du Hêtre).

Chapitre 2. Qualités et utilisations du bois de Hêtre aujourd'hui.

Chapitre 3. Itinéraires sylvicoles en futaie régulière (y compris la conversion, et les boisements de Hêtre sur terre agricole).

Chapitre 4. Vers la futaie irrégulière (avec deux exemples bien différents, dans l'Est de la France).

Chapitre 5. Le Hêtre dans la culture française (le mot Hêtre au fil des siècles, représentation en peinture, évocation en littérature, etc.).

Annexe 1. Sélection de bonnes stations à Hêtre dans les 4 régions de France (Lorraine, Midi-Pyrénées/ Aquitaine, Normandie, Nord-Pas-de-Calais).

Annexe 2. Les habitats liés au Hêtre (onze sont décrits, avec appellation phytosociologique).

Annexe 3. Utilisation du matériel végétal de reproduction ; recherche et réglementation (y compris la révision des régions de provenance de 1999).

Annexe 4. Les principaux problèmes phytosanitaires du Hêtre.

Annexe 5. Les normes européennes de classement des bois ronds de Hêtre.

Annexe 6. Hêtre et cervidés : de vrais "faux amis".

Annexe 7. Reconstitution des hêtraies après les tempêtes de décembre 1999.

L'ensemble constitue un manuel d'un genre nouveau, concis et clair, auquel nous souhaitons le succès qu'il mérite.

Adresse de l'éditeur : Institut pour le Développement forestier - Service Édition-Diffusion - 23, avenue Bosquet - F-75007 PARIS. 